\title{
Bile acid malabsorption in chronic diarrhea: Pathophysiology and treatment
}

\author{
Alan Barkun $M D^{1}$, Jonathan Love $\mathrm{MD}^{2}$, Michael Gould $\mathrm{MD}^{3}$, Henryk Pluta $\mathrm{MD}^{4}$, A Hillary Steinhart $\mathrm{MD}^{5}$
}

\begin{abstract}
A Barkun, J Love, M Gould, H Pluta, AH Steinhart. Bile acid malabsorption in chronic diarrhea: Pathophysiology and treatment. Can J Gastroenterol 2013;27(11):653-659.
\end{abstract}

BACKGROUND: Bile acid malabsorption (BAM) is a common but frequently under-recognized cause of chronic diarrhea, with an estimated prevalence of $4 \%$ to $5 \%$.

METHODS: The published literature for the period 1965 to 2012 was examined for articles regarding the pathophysiology and treatment of BAM to provide an overview of the management of BAM in gastroenterology practice.

RESULTS: BAM is classified as type 1 (secondary to ileal dysfunction), type 2 (idiopathic) or type 3 (secondary to gastrointestinal disorders not associated with ileal dysfunction). The estimated prevalence of BAM is $>90 \%$ in patients with resected Crohn disease (CD) and $11 \%$ to $52 \%$ of unresected CD patients (type 1 ); $33 \%$ in diarrheapredominant irritable bowel syndrome (type 2); and is a frequent finding postcholecystectomy or postvagotomy (type 3). Investigations include BAM fecal bile acid assay, 23-seleno-25-homo-tauro-cholic acid (SeHCAT) testing and high-performance liquid chromatography of serum 7- $\alpha-\mathrm{OH}$-4-cholesten-3-one (C4), to determine the level of bile acid synthesis. A less time-consuming and expensive alternative in practice is an empirical trial of the bile acid sequestering agent cholestyramine. An estimated $70 \%$ to $96 \%$ of chronic diarrhea patients with BAM respond to short-course cholestyramine. Adverse effects include constipation, nausea, borborygmi, flatulence, bloating and abdominal pain. Other bile acid sequestering agents, such as colestipol and colesevelam, are currently being investigated for the treatment of BAM-associated diarrhea.

CONCLUSIONS: BAM is a common cause of chronic diarrhea presenting in gastroenterology practice. In accordance with current guidelines, an empirical trial of a bile acid sequestering agent is warranted as part of the clinical workup to rule out BAM.

Key Words: Bile acid malabsorption; Cholestyramine; Chronic diarrhea; Enterohepatic circulation; FGF19; SeHCAT

\section{La malabsorption de l'acide biliaire en cas de diarrhée chronique : la physiopathologie et le traitement}

HISTORIQUE : La malabsorption de l'acide biliaire (MAB) est une cause de diarrhée chronique fréquente mais souvent sous-diagnostiquée, dont la prévalence est évaluée entre $4 \%$ et $5 \%$.

MÉTHODOLOGIE : Les chercheurs ont examiné les publications de 1965 à 2012 pour en extraire les articles portant sur la physiopathologie et le traitement de la MAB en gastroentérologie.

RÉSULTATS : La MAB est divisée en type 1 (secondaire à une dysfonction iléale), type 2 (idiopathique) et type 3 (secondaire à des troubles gastro-intestinaux non associés à une dysfonction iléale). La prévalence estimée de la MAB dépasse les $90 \%$ chez les patients ayant une résection causée par la maladie de Crohn (MC) et se situe entre $11 \%$ et $52 \%$ chez les patients atteints d'une MC sans résection (type 1). Elle correspond à $33 \%$ en cas de syndrome du côlon irritable qui se manifeste surtout par de la diarrhée (type 2) et est fréquente après une cholecystectomie ou une vagotomie (type 3 ). Les examens incluent le titrage de l'acide biliaire fécale, de l'acide 23-séléno-25-homotaurocholique (SeHCAT) et de la chromatographie à haute performance du sérum 7- $\alpha$-OH-4-cholesten-3-one (C4) causés par la MAB, afin de déterminer le taux de synthèse de l'acide biliaire. En pratique, une solution moins chronophage et moins coûteuse consiste à procéder à un essai empirique de la cholestyramine, l'agent séquestrant des acides biliaires. On estime que de $70 \%$ à $96 \%$ des patients atteints de diarrhée chronique présentant une MAB répondent à un court traitement à la cholestyramine. Les effets indésirables incluent la constipation, les nausées, les borborygmes, les flatulences, les gonflements et les douleurs abdominales. D'autres agents séquestrants des acides biliaires, comme le colestipol et le colésévélam, sont en cours d'évaluation en vue du traitement de la diarrhée associée à la MAB.

CONCLUSIONS : La MAB est une cause fréquente de diarrhée chronique en gastroentérologie. Conformément aux directives à jour, un essai empirique de l'agent séquestrant des acides biliaires s'impose dans le cadre du bilan clinique pour écarter la MAB.

gastrointestinal infection or food poisoning. The most common causes in clinical practice are inflammatory syndromes of the small bowel or colon (eg, Crohn disease [CD], celiac disease); functional bowel disorders (eg, irritable bowel syndrome [IBS]); neoplasia; pancreatic insufficiency resulting in maldigestion; intestinal dysmotility; and small bowel malabsorption (eg, postgastrointestinal surgery) (Table 1).

A common but frequently underinvestigated cause of chronic diarrhea is bile acid malabsorption (BAM) resulting from dysregulation of the enterohepatic recycling of bile acids and of bile acid production. The present review summarizes recent developments in the pathophysiology, investigation and treatment of BAM, and addresses its relevance to the clinical management of chronic diarrhea. Chronic symptoms generally do not suggest an infectious etiology although patients may report that symptoms are preceded by

\footnotetext{
${ }^{1}$ Division of Gastroenterology, McGill University, Montreal, Quebec; ${ }^{2}$ Division of Gastroenterology, University of Calgary, Calgary, Alberta;

${ }^{3}$ Toronto Digestive Disease Associates Inc, Toronto, Ontario; ${ }^{4}$ Gastroenterology and Hepatology Clinic, Abbotsford, British Columbia;

${ }^{5}$ Division of Gastroenterology, Mount Sinai Hospital and the University Health Network, Toronto, Ontario

Correspondence: Dr Alan Barkun, McGill University, Room D7.185, 1650 Cedar Avenue, Montreal, Quebec H3G 1 A4.

Telephone 514-934-8233, fax 514-934-8375, e-mail alan.barkun@muhc.mcgill.ca

Received for publication January 24, 2013. Accepted August 26, 2013
} 


\begin{tabular}{ll} 
TABLE 1 & \\
Potential causes & of chronic diarrhea in clinical practice \\
\hline Colon & Colonic neoplasia \\
& Inflammatory bowel disease (ulcerative colitis, \\
& Crohn's colitis) \\
& Microscopic colitis \\
Small bowel & Celiac disease \\
& Crohn disease \\
& Other small bowel enteropathies \\
& Bile acid malabsorption \\
& Disaccharidase deficiency \\
& Small bowel bacterial overgrowth \\
& Mesenteric ischemia \\
& Radiation enteritis \\
& Lymphoma \\
& Chronic infection (eg, giardiasis) \\
& Chronic pancreatitis \\
& Pancreatic carcinoma \\
& Cystic fibrosis \\
Hyperthyroidism & Diabetes \\
Pypoparathyroidism & Addison disease \\
Hormone-secreting tumours (eg, VIPoma, carcinoid, \\
gastrinoma) \\
Factitious diarrhea \\
Surgery (eg, small bowel resection, internal fistulas) \\
Drugs (eg, nonsteroidal anti-inflammatory drugs, \\
antihypertensives, antibiotics, antiarrhythmics, \\
antineoplastics, drugs containing magnesium) \\
Food additives (eg, sorbitol, fructose) \\
Alcohol abuse \\
Autonomic neuropathy \\
Other
\end{tabular}

Adapted from reference 1

\section{METHODS}

For the present narrative review, the PubMed database was searched using a combination of controlled vocabulary and text words to identify reports related to bile acid diarrhea for the period October 1965 to October 2012. The search terms "bile acid malabsorption" filtered for "Humans" obtained 923 results, which were manually searched for relevance to providing an overview of the pathophysiology, investigation and treatment of BAM. Supplemental information was obtained through secondary searches using the terms "chronic diarrhea", "inflammatory bowel disease" or "IBD", "irritable bowel syndrome" or "IBS", "enterohepatic circulation", "cholestyramine", "colestipol” and "colesevelam".

Bile acid production and the enterohepatic circulation

The enterohepatic circulation of bile acids was first described by Small et al (6) four decades ago (Figure 1). Primary bile acids, principally cholic acid (CA) and chenodeoxycholic acid (CDCA), are synthesized from cholesterol in the liver, conjugated with glycine or taurine to increase their water solubility and secreted to bile. Secondary bile acids, primarily deoxycholic acid (DCA) and lithocholic acid, are derived from primary bile acids as a result of modifications (eg, deconjugation, 7-dehydroxylation) by intestinal bacteria. These modifications increase passive absorption of secondary bile acids in the colon.

The main pathway for cholesterol conversion to CA and CDCA is the neutral pathway, in which the rate-limiting enzyme is the cytochrome P450 enzyme cholesterol 7 $\alpha$-hydroxylase (CYP7A1) (7). In the alternative (acidic) pathway, 27-hydroxylation of bile acid intermediates of the CYP7A1 pathway primarily results in CDCA synthesis; this pathway accounts for $<20 \%$ of total bile acid production (8). Other minor pathways involve cholesterol 25-hydroxylase, which is not part of the CYP450 system; and cholesterol 24-hydroxylase (CYP46), which converts 24S-cholesterol in the brain to bile acids (7).

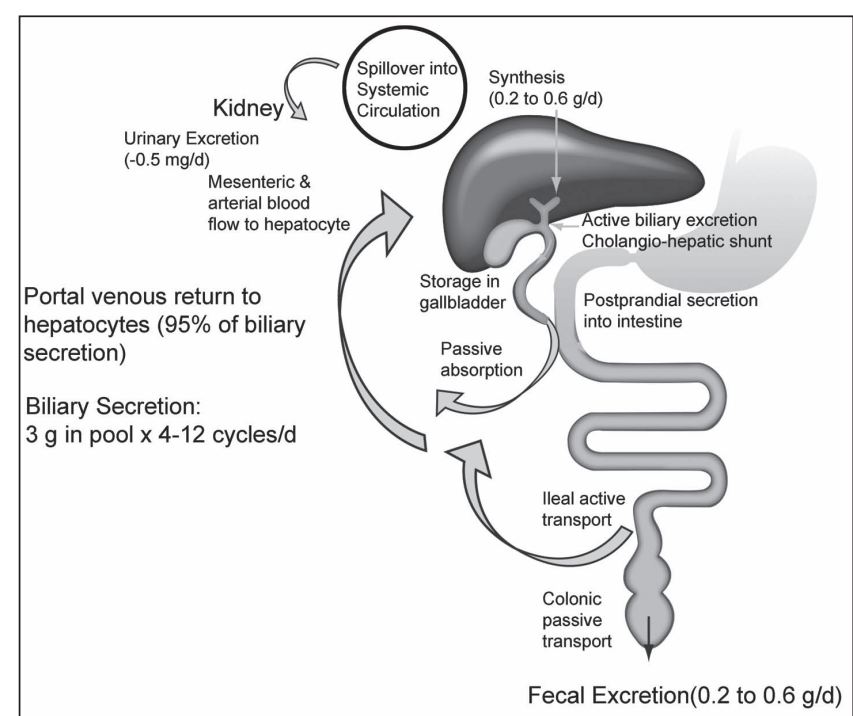

Figure 1) Enterohepatic circulation of bile acids. Reprinted with permission from reference 24. d Day

Approximately $95 \%$ of primary bile acids are reabsorbed by the distal ileum through active uptake by the apical sodium-dependent bile acid transporter (ASBT), returned to the liver via the portal circulation and taken up by hepatocytes. A small percentage of bile acids entering the colon can be passively absorbed, resulting in an overall net loss of $1 \%$ to $3 \%$ (9). The conservation of the bile acid pool is altered by more rapid intestinal transit and changes in gut flora due to diet, medications or other factors.

Cholesterol and bile acid levels are tightly regulated. Of particular interest are the liver $\mathrm{X}$ receptor and the farnesoid X receptor (FXR), both of which act as transcription factors regulating enzyme expression. The dimerized liver $\mathrm{X}$ receptor/retinoid X receptor (RXR) binds to oxidized cholesterol metabolites and induces the expression of CYP7A1, resulting in increased bile acid synthesis $(7,10)$.

Bile acid production is regulated by FXR, which is expressed primarily in ileal enterocytes and hepatocytes (Figure 2). Bile acids activate FXR, which forms a dimerized FXR/RXR complex. In the liver, FXR/RXR downregulates CYP7A1 expression, resulting in decreased bile acid synthesis and increased expression of the bile salt export pump, and downregulates CYP8B1, which is necessary for CA synthesis $(11,12)$. The result is a decrease in bile acid synthesis and uptake, and increased export to bile (10). In enterocytes, FXR/RXR acts on ASBT to reduce ileal uptake of bile acids (13). High intracellular bile acid levels in enterocytes also stimulate the release of fibroblast growth factor 19 (FGF19), which feeds back to the FGF receptor-4 (FGFR4) and its coreceptor Klotho $\beta$ on hepatocytes to downregulate CYP7A1 and reduce bile acid production $(14,15)$. This decreases intestinal bile acid absorption and prevents the intracellular accumulation of bile acids. Thus, bile acid production is regulated through negative feedback mechanisms in the liver and remotely in the ileum.

The composition of the bile acid pool is influenced by various factors. The principal constituents are the primary bile acids (CA, CDCA) and the secondary bile acid DCA; DCA accumulates in the bile pool because 7-dehydroxylation cannot be reversed (10). DCA formation from CA is increased by diet (eg, high fat) and other factors that slow colonic transit times (10), as well as increased Gram-positive anaerobes and 7-alpha-dehydroxylase activity (16). Absorption and bioavailability of DCA are influenced by colonic transit time and $\mathrm{pH}$ in the distal colon (16).

Diets high in taurine (eg, seafood), or high in fat or low in fibre will increase the amount of taurine-conjugated bile acids $(17,18)$. The ASBT is also more effective at transporting dihydroxy bile acids (ie, DCA, CDCA) (13), which influence the bile acid pool. 


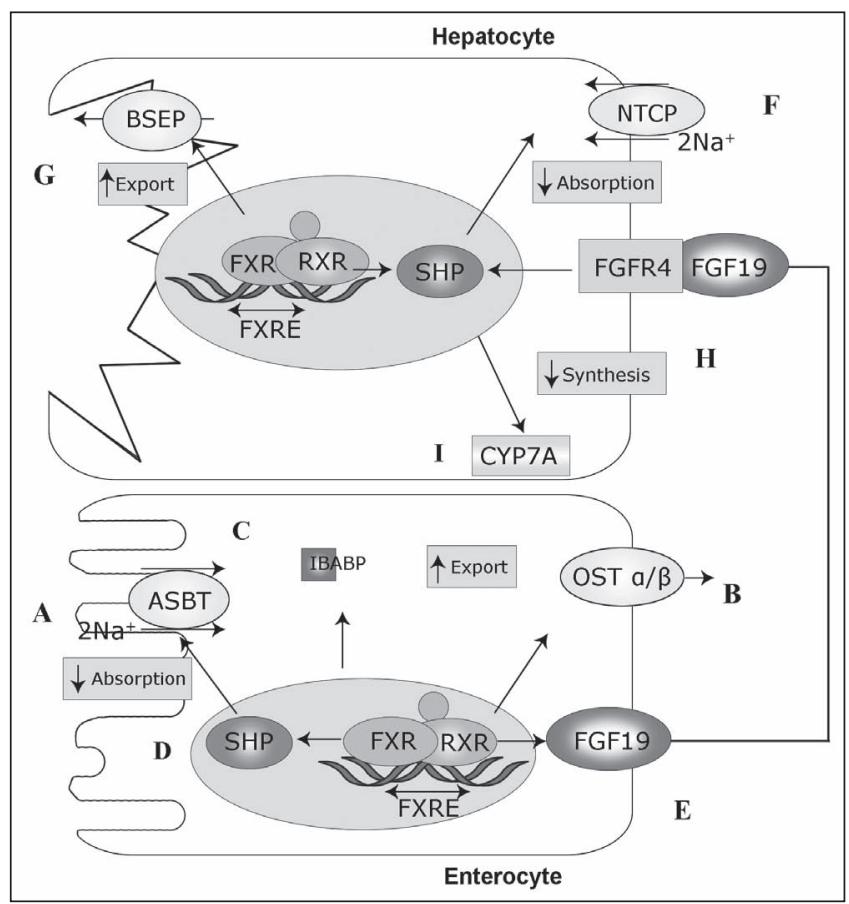

Figure 2) Regulation of bile acid (BA) absorption and transport. Adapted and used with permission from reference 10 . In ileal enterocytes, farnesoid $X$ receptor $(F X R)$-retinoid $X$ receptor $(R X R)$ regulates $B A$ homeostasis by reducing $B A$ uptake by the apical sodium-dependent bile acid transporter $(\mathrm{ASBT})$, reducing intestinal absorption of $\mathrm{BAs}(\mathrm{A})$; and $(\mathrm{B})$ increasing $B A$ export by organic solute transporter alpha/beta (OST $\alpha / \beta)$, reducing intracellular accumulation of BA. C Ileal bile acid binding protein (IBABP) is involved in FXR expression. D FXR effects are mediated by small heterodimer partner (SHP). E Ileal FXR also regulates BA production via fibroblast growth factor (FGF) 19. F In hepatocytes, intracellular BA levels are regulated by $\mathrm{Na}^{+}$taurocholate cotransporting polypeptide transporter (NTCP) and (G) the bile salt export pump (BSEP). H FGF19 activates FGFR4. I FGF receptor 4 (FGFR4) via FXR-RXR downregulates cholesterol 7 $\alpha$-hydroxylase (CYP7A) synthesis of BAs

Medications also play a role. Glucocorticoids upregulate ASBT (19), suggesting an alternative mechanism of symptom control in patients with inflammatory bowel disease. Cholestyramine has been shown to preferentially reduce dihydroxy (CDCA, DCA) bile acids (eg, CA) and reduce the secondary bile acid pool (20). Cholestyramine also elevates the ratio of glycine- versus taurine-conjugated bile acids in bile. Because glycine conjugates are more subject to passive absorption, this may be an alternative mechanism by which cholestyramine reduces malabsorption (20).

Some bile acids (eg, CA, ursoDCA) do not appear to contribute to diarrhea (10). Dihydroxy bile acids (eg, DCA, CDCA) are more active, causing mucosal damage and demonstrating prosecretory effects in the colon (21-23).

\section{BAM}

An estimated $0.5 \mathrm{~g}$ of bile acids are synthesized in the liver per day (24). The total bile acid pool is approximately $3 \mathrm{~g}$, of which $95 \%$ is reclaimed from the ileum and a small amount of unconjugated bile acids is recaptured in the colon via passive nonionic diffusion (25). This cycle is repeated four to 12 times per day, resulting in an estimated daily loss of $0.2 \mathrm{~g} /$ day to $0.6 \mathrm{~g} /$ day in the feces, which must be replaced by new bile acid synthesis in hepatocytes (24).

Excessive levels of bile acids in the lower gastrointestinal tract may cause diarrhea via one or more mechanisms: altering water and sodium

\section{TABLE 2}

Classification of bile acid malabsorption (BAM)

\begin{tabular}{|c|c|}
\hline Classification of BAM & Etiology \\
\hline Type 1 & Ileal Crohn disease, ileal resection \\
\hline $\begin{array}{l}\text { Ileal dysfunction } \\
\text { (secondary BAM) }\end{array}$ & $\begin{array}{l}\text { - Results in failure to reabsorb BAs at the distal } \\
\text { ileum leading to BA spillover into colon }\end{array}$ \\
\hline Type 2 & Unknown cause \\
\hline $\begin{array}{l}\text { Idiopathic BAM/primary } \\
\text { bile acid diarrhea }\end{array}$ & $\begin{array}{l}\text { - No consistent inherited abnormality in transporter } \\
\text { proteins }\end{array}$ \\
\hline & $\begin{array}{l}\text { - Mechanisms may arise from defect in negative } \\
\text { feedback (FGF19) regulation in the synthesis } \\
\text { of BAs, leads to overproduction of BAs }\end{array}$ \\
\hline \multirow[t]{2}{*}{$\begin{array}{l}\text { Type } 3 \\
\text { Other conditions }\end{array}$} & $\begin{array}{l}\text { Postcholecystectomy, postvagotomy, celiac disease, } \\
\text { bacterial overgrowth, pancreatic insufficiency } \\
\text { (chronic pancreatitis and cystic fibrosis) }\end{array}$ \\
\hline & $\begin{array}{l}\text { - May involve alterations in small intestinal motility, } \\
\text { altered BA cycling, or composition of ileal } \\
\text { contents }\end{array}$ \\
\hline
\end{tabular}

Adapted from reference 27. BA Bile acid; FGF Fibroblast growth factor

transport; increasing lower gastrointestinal motility; damaging the mucosa; inducing mucus secretion; or stimulating defecation $(22,26,27)$.

Three subtypes of BAM have been categorized. Type 1 includes patients with terminal ileal disease (eg, CD, resection) or radiation injury resulting in impaired bile acid reabsorption; type 2 is idiopathic; and type 3 comprises conditions unrelated to ileal disease (eg, celiac disease, cholecystectomy, bacterial overgrowth) that alter intestinal motility or bile acid absorption (Table 2) (26).

BAM is often regarded as a rare phenomenon, reflected in a survey of gastroenterologists in the United Kingdom (28). One-third of new patients presented with chronic diarrhea. BAM was considered in the diagnostic workup in $22 \%$ of chronic diarrhea cases. Overall, only $1 \%$ of all new cases and 3\% of chronic diarrhea cases were diagnosed with BAM; among BAM cases, 61\% were type 1, 22\% were type 2 and 15\% were type 3 . Thirty-nine per cent of clinicians investigated only a selected group of patients, and $22 \%$ reported they investigated BAM rarely or not at all.

Often under-recognized in practice is type 2 BAM (idiopathic BAM), which potentially affects a wide range of patients with chronic diarrhea. While the etiology of idiopathic BAM is unclear, several underlying pathophysiological mechanisms have been proposed. Some (29-31), but not all (32), studies have suggested that idiopathic BAM is associated with more rapid small-bowel and colonic transit times. Genetic variants in the FGF19-FGFR4-Klotho $\beta$ pathway, which affects colonic transit times, have been reported in diarrhea-predominant IBS (IBS-D) (33). However, these variants may play a more important role in dysregulation of the bile acid pool. A recent study reported that $38 \%$ of IBS-D patients exhibited increased bile acid synthesis, as measured by serum levels of 7 $\alpha$-hydroxy-4-cholesten-3-one (C4), and higher body mass index (34).

Similar results were found in a study comparing idiopathic BAM patients with diarrhea versus healthy controls (35). Fasting C4 levels were significantly higher in patients with idiopathic BAM compared with controls ( $51 \mathrm{ng} / \mathrm{mL}$ versus $18 \mathrm{ng} / \mathrm{mL}$ ), suggesting dysregulation of bile acid synthesis. Moreover, median FGF19 levels were significantly lower in idiopathic BAM versus controls (120 pg/mL versus $231 \mathrm{pg} / \mathrm{mL}$ ), indicating that a deficiency in FGF19 feedback inhibition of bile acid synthesis may contribute to an overproduction of bile acids that cannot be accommodated by ileal reabsorption. FGF19 levels were also found to be low in patients postcholecystectomy (type 3 BAM).

\section{BAM investigations}

Traditional investigations of BAM, such as direct testing of bile acid content in fecal samples $(36,37)$ or ${ }^{14} \mathrm{C}$ cholylglycine testing of ${ }^{14} \mathrm{C}$ in expired air and stool, are difficult and unpleasant to perform (38). Another method to assess BAM is SeHCAT testing (sensitivity $>80 \%$, specificity $>98 \%)(39,40)$, in which 23 -selena-25-homo- 
TABLE 3

Prevalence of idiopathic bile acid malabsorption (BAM) (type 2) in patients with unexplained chronic diarrhea or diarrheapredominant irritable bowel syndrome (IBS-D)

\begin{tabular}{|c|c|c|c|c|c|}
\hline Author (reference), year & Patient group & $\mathbf{n}$ & SeHCAT at 7 days, $\%$ & BAM prevalence, $\%$ & Response to cholestyramine, \% \\
\hline \multirow[t]{3}{*}{ Ford et al (53), 1992} & \multirow[t]{3}{*}{ Idiopathic chronic diarrhea } & \multirow[t]{3}{*}{74} & \multirow[t]{3}{*}{$<15$} & \multirow[t]{3}{*}{27.0} & $92.5(\mathrm{SeHCAT}<5)$ \\
\hline & & & & & 41.4 (SeHCAT 5-10) \\
\hline & & & & & 46.7 (partial response only) \\
\hline Sinha et al (54). 1998 & Idiopathic BAM & 9 & $<15$ & $n / a$ & 667 \\
\hline Sciarretta et al (32), 1987 & IBS-D, postcholecystectomy & 46 & $<8$ & $39 *$ & 43.4 \\
\hline Cramp et al (56), 1996 & $\begin{array}{l}\text { Chronic diarrhea secondary to } \\
\text { HIV infection }\end{array}$ & 19 & $<15$ & $84.2^{*}$ & 84.6 \\
\hline Ung et al (57), 2000 & Idiopathic chronic diarrhea & 94 & $<10$ & 44.7 & $\mathrm{n} / \mathrm{a}$ \\
\hline Smith et al (58), 2000 & IBS-D & 197 & $<10$ & 33.5 & 70.0 \\
\hline Wildt et al (59), 2003 & Idiopathic chronic diarrhea & 133 & $<15$ & $56^{*}$ & $\mathrm{n} / \mathrm{a}$ \\
\hline \multirow{2}{*}{$\begin{array}{l}\text { Fernández-Bañares et al } \\
(61), 2007\end{array}$} & \multirow[t]{2}{*}{ Chronic watery diarrhea } & \multirow[t]{2}{*}{62} & \multirow[t]{2}{*}{$<11$} & \multirow[t]{2}{*}{59.7} & 45.2 (all) \\
\hline & & & & & 75.8 (BAM) \\
\hline \multirow[t]{4}{*}{ Wedlake et al (62), 2009} & \multirow[t]{4}{*}{ IBS-D } & \multirow[t]{4}{*}{$1223^{\dagger}$} & SeHCAT & & \\
\hline & & & $<5$ & 10 & $96(\mathrm{SeHCAT}<5)$ \\
\hline & & & $<10$ & 32 & $80($ SeHCAT <10) \\
\hline & & & $<15$ & 26 & 70 (SeHCAT <15) \\
\hline \multirow[t]{3}{*}{ Borghede et al (49), 2011} & \multirow[t]{3}{*}{ Idiopathic chronic diarrhea } & \multirow[t]{3}{*}{114} & \multirow[t]{3}{*}{$<15$} & \multirow[t]{3}{*}{59.6} & $74.3(\mathrm{SeHCAT}<5)$ \\
\hline & & & & & 85.7 (SeHCAT 5-10) \\
\hline & & & & & 50.0 (SeHCAT 11-15) \\
\hline Kurien et al (63), 2011 & IBS-D & 273 & $<10$ & 39.2 & $\mathrm{n} / \mathrm{a}$ \\
\hline \multirow[t]{2}{*}{ Gracie et al (64), 2012} & \multirow[t]{2}{*}{ Idiopathic chronic diarrhea } & 373 & \multirow[t]{2}{*}{$<15$} & $50.9 *$ & $\mathrm{n} / \mathrm{a}$ \\
\hline & & & & 27.3 (IBS-D) & \\
\hline
\end{tabular}

*Included patients with type 1 and/or type 3 BAM; ' Systematic review of 18 studies. n/a Not applicable; SeHCAT 23-seleno-25-homo-tauro-cholic acid

tauro-cholic acid is radiolabelled with ${ }^{75}$ Selenium homotaurocholic acid (41). This orally administered synthetic conjugated bile acid is secreted in bile, reabsorbed in the terminal ileum and resecreted. A noncollimated gamma camera measures abdominal radioactivity on day 7. Early studies indicated that retention of $<12 \%$ of 23 -selena25 -homotaurocholic acid was abnormal (42). A cut-off value $<10 \%$ to $15 \%$ retention at day 7 is now generally established. SeHCAT testing has proven invaluable in the research setting, but is not routinely available in practice. This is unfortunate because the cost of the test is comparable with other, more routine, studies. SeHCAT costs $\$ 250$ per capsule while an octreotide scan costs $\$ 1,028$ per dose, and a $99 \mathrm{mTc}$ methylene diphosphonate bone scan costs $\$ 28$ (personal communication, J Love, Foothills Medical Centre Nuclear Medicine Department, Calgary, Alberta). SeHCAT values are stable during long-term followup in patients with chronic diarrhea, suggesting that repeat testing is not required (43).

Determining the serum levels of $\mathrm{C} 4$, which are markedly elevated when bile acid synthesis is increased (44-46), is a potentially useful measure but is not widely used at present; further standardization is needed (47). ELISA of serum FGF19 levels, which are inversely correlated with C4 levels, has been proposed (35) but is not generally available.

It should be noted that pathophysiological mechanisms other than BAM may contribute to diarrhea in some patients (eg, postcholecystectomy) with abnormal SeHCAT or C4 findings (48), and that abnormal SeHCAT/C4 may occur in patients without clinically relevant symptoms. The association among SeHCAT, BAM and symptom frequency/severity requires further study.

A practical alternative to SeHCAT/C4 testing of BAM in patients with chronic diarrhea is to use a bile acid sequestering agent, which binds with high affinity to organic anions such as bile acids. American Gastroenterology Association guidelines recommend an empirical trial with an agent, such as cholestyramine, to diagnose BAM (49). British Society of Gastroenterology guidelines state that in the absence of diagnostic tests, an empirical trial of cholestyramine can be used (1), with the caveat that this approach has not been prospectively studied.

\section{Prevalence of type 1 BAM}

BAM secondary to ileal dysfunction is common. A retrospective review of 298 patients with chronic watery diarrhea found seven-day SeHCAT retention to be $<10 \%$ in 15 of 29 patients $(51.7 \%)$ with unresected CD, 40 of 43 patients $(93.0 \%)$ with resected CD, 12 of 12 patients $(100 \%)$ following small bowel resection and two of three patients $(66.7 \%)$ following radiation injury (49). Lenicek et al (50) reported that BAM severity was associated with the extent of ileal resection in CD patients. Elevated C4 levels were detected in $61.7 \%$ of resected CD patients, and less commonly in unresected ileitis or colitis patients (14\% and $11 \%$, respectively) $(50,51)$. In an analysis of CD patients referred for SeHCAT testing for chronic diarrhea refractory to antidiarrheal medications or steroids, SeHCAT retention $<5 \%$ was found in $90 \%$ of resected and $28 \%$ of unresected CD patients (52).

Prevalence of type 2 BAM in idiopathic chronic diarrhea SeHCAT testing has proven to be a useful research tool to detect BAM in patients with unexplained chronic diarrhea (49,53-74). The estimated prevalence of idiopathic BAM in chronic diarrhea ranges from $37.5 \%$ to $59.6 \%$ (Table 3 ).

Approximately one-third of patients with a diagnosis of IBS-D have underlying BAM (Table 3). A systematic review of 18 studies $(n=1223)$ reported that $10 \%$ of patients had BAM using a cut-off value of SeHCAT $<5 \%$ of baseline (severe BAM) (62). Approximately $32 \%$ had BAM using a cut-off of SeHCAT $<10 \%$ (severe and moderate BAM), and $26 \%$ had some degree of BAM (SeHCAT $<15 \%$; severe, moderate and mild BAM).

Idiopathic BAM associated with postinfective diarrhea is another interesting area of study. A case review found 16 of 29 patients (55\%) with a positive SeHCAT test had a history of acute gastroenteritis before the onset of chronic diarrhea (65). Similarly, a retrospective analysis of 135 patients with SeHCAT < $10 \%$ identified 25 cases of postinfective BAM responsive to cholestyramine (66). The precise mechanisms leading to postinfective BAM require further elucidation. 


\section{Prevalence of type 3 BAM}

Type 3 BAM is common in patients with a variety of gastrointestinal disorders not associated with ileal dysfunction. BAM appears to be related to impaired bicarbonate secretion in patients with chronic pancreatitis (67). In celiac disease, BAM has been attributed to atrophy of the small intestinal mucosa, and impairments in gall bladder and small bowel motor function (68).

$\mathrm{BAM}$ is a frequent complication following gall bladder surgery, with one case series reporting a marked degree of BAM in 25 of 26 patients with postcholecystectomy diarrhea (69). While fecal bile acid loss has been documented in this setting, one study found that rising $\mathrm{C} 4$ levels did not appear to be related to a change in bowel habits (70). Animal studies have reported a significant increase in bile acid production and an increased proportion of secondary bile acids following cholecystectomy and ileal resection (71), suggesting that severe disruption of the enterohepatic circulation postsurgery results in chronic diarrhea. BAM may also be a contributing factor in patients with postvagotomy diarrhea (72), although the mechanisms are poorly understood.

\section{Response to bile acid sequestering agents}

A large proportion of patients with severe BAM (SeHCAT $<5 \%)$ will respond to an empirical trial of cholestyramine (Olestyr; Pendopharm, Canada). In the case series reported by Nyhlin et al (52), response rates were $88 \%$ in resected CD and $28 \%$ in unresected CD. A total of 37 of 40 patients with severe BAM (all types) responded to cholestyramine $1 \mathrm{~g} /$ day to $8 \mathrm{~g} /$ day in the series by Ford et al (53). A large series demonstrated a response in $71 \%$ of patients taking cholestyramine; treatment with a bile acid sequestering agent was effective regardless of BAM type (49).

In addition, a substantial proportion of patients with IBS-D will respond to cholestyramine. In their systematic review of 15 treatment studies, Wedlake et al (62) found that clinical response was correlated with BAM severity. The overall response to empirical therapy with cholestyramine was $96 \%$ for severe BAM (SeHCAT <5\% of baseline), $80 \%$ for moderate or severe BAM (SeHCAT $<10 \%$ ), and $70 \%$ for any degree of BAM (SeHCAT <15\%). Because one-quarter of IBS-D patients have some degree of BAM, it would be expected that a large proportion of patients would respond to empirical use of cholestyramine. Wedlake et al (62) concluded that BAM is not a rare finding in IBS-D patients and speculated that as many as 500,000 adults in the United Kingdom could benefit from therapeutic intervention for bile acid malabsorption. A similar number of Canadians would be expected to benefit from treatment due to the higher prevalence of IBS-D in Canada (73).

A long-term follow-up (mean 99 months) of 14 patients with chronic diarrhea (74) found that seven of 14 experienced resolution of symptoms and no longer required cholestyramine. Of the remaining seven symptomatic patients, diarrhea was well controlled in five using cholestyramine and in two using antidiarrheal medications.

Cholestyramine is the only agent approved by Health Canada for the symptomatic control of bile acid-induced diarrhea due to short bowel syndrome to help reduce fecal bile acid loss (75). Cholestyramine powder is usually administered at a starting dose of $4 \mathrm{~g} /$ day, increased as needed to $4 \mathrm{~g}$ one to six times/day; in clinical practice, less frequent dosing (eg, $4 \mathrm{~g}$ twice/day) is often effective in relieving BAMassociated diarrhea. Lower doses (eg, $4 \mathrm{~g}$ twice/day) are generally used in patients with short-bowel syndrome. Adverse effects may include constipation, nausea, borborygmi, flatulence, bloating and abdominal pain.

The bile acid sequestering agents colestipol (Colestid; Pfizer, Canada) and colesevelam (Lodalis, Welchol; Daiichi Sankyo, Japan) would also be expected to be clinically useful based on their mode of action; however, neither is indicated for the treatment of BAMassociated diarrhea in Canada (76,77). There are no published reports of colestipol in BAM. Dosing for hyperlipidemia is $2 \mathrm{~g} /$ day to $16 \mathrm{~g} /$ day administered either once-daily or in divided doses, or one to six packets $(5 \mathrm{~g} /$ packet or $7.5 \mathrm{~g} /$ packet $)$ of colestipol given once-daily or in divided doses. The most common adverse effects are constipation, abdominal pain/cramping, bloating/flatulence, heartburn, diarrhea and nausea/vomiting.
Colesevelam, a water-insoluble polymer, has been shown to have modest effects on intestinal transit time. A study randomly assigned 24 patients with IBS-D to colesevelam $1.875 \mathrm{~g}$ twice/day or placebo for 12 to 14 days. Colesevelam eased stool passage and had a nonsignificant effect on $24 \mathrm{~h}$ colonic transit time $(\mathrm{P}=0.22)$. There was no effect on the number of bowel movements per day; however, there was a tendency to improved stool consistency (78). A retrospective study in cancer patients with BAM symptoms receiving colesevelam reported improvements in diarrhea (83\%), urgency of defecation $(74 \%)$, frequency of defecation (72\%), steatorrhea (71\%), abdominal pain (68\%) and fecal incontinence (62\%) (79). The optimal dosing of colesevelam for BAM has not been established. The dosing for hyperlipidemia is six $625 \mathrm{mg}$ tablets/day (or three tablets twice per day), or one $3.75 \mathrm{~g}$ packet/day (or $1.875 \mathrm{~g}$ packet twice/day). The most common adverse effects are constipation, dyspepsia and nausea.

All bile acid sequestering agents have the potential to bind other drugs. Interactions may occur with drugs such as glyburide, glimepiride, glipizide, tetracycline, penicillin G, levothyroxine, cyclosporine, olmesartan, phenobarbital, warfarin, digitalis, and oral contraceptives containing ethinyl estradiol and norethindrone (75-77). Patients should generally be advised to take medications either $1 \mathrm{~h}$ before or $4 \mathrm{~h}$ to $6 \mathrm{~h}$ after the bile acid sequestering agent (80).

In addition, bile sequestering agents may interfere with the absorption of fat-soluble vitamins $(81,82)$. During long-term use, periodic monitoring of serum vitamin $\mathrm{A}$ and $\mathrm{E}$ levels and prothrombin time are advised.

\section{CONCLUSIONS}

BAM is a frequently overlooked condition in patients with chronic diarrhea. BAM may be suspected in patients with persistent symptoms of watery diarrhea, notably in patients with ileal disease or following gastrointestinal surgery. Idiopathic BAM is a contributing factor in approximately one-third of patients presenting with IBS-D. While the etiology is not fully understood, alterations in the enterohepatic circulation, accelerated intestinal transit, an increase in the bile acid pool, and insufficient FGF19 levels appear to contribute to the onset and persistence of chronic diarrhea symptoms.

Because objective testing with SeHCAT or C4 is not widely available in gastroenterology practice, an empirical trial of a bile acid sequestering agent, such as cholestyramine, should be used to rule out underlying BAM as part of the clinical work-up of patients with chronic diarrhea, as currently recommended by American Gastroenterological Association and British Society of Gastroenterology guidelines.

DISCLOSURES: The authors have no financial disclosures or conflicts of interest to declare.

ACKNOWLEDGEMENTS: Editorial assistance was provided by Steven Manners of Communications Lansdowne through a grant from Pendopharm, a division of Pharmascience Inc.

\section{REFERENCES}

1. Thomas PD, Forbes A, Green J, et al. Guidelines for the investigation of chronic diarrhoea, 2 nd edn. Gut 2003;52(Suppl V):v1-v15.

2. Talley NJ, Weaver AL, Zinsmeister AR, Melton LJ III. Onset and disappearance of gastrointestinal symptoms and functional gastrointestinal disorders. Am J Epidemiol 1992;136:165-77.

3. Talley NJ, O'Keefe EA, Zinsmeister AR, Melton LJ III. Prevalence of gastrointestinal symptoms in the elderly: A population-based study. Gastroenterology 1992;102:895-901.

4. Schiller LR. Diarrhea and malabsorption in the elderly. Gastroenterol Clin North Am 2009;38:481-502.

5. Canadian Digestive Health Foundation. Diarrhea information sheet. < www.cdhf.ca/pdfs/fact-sheets/CDHF_FactSheet_Diarrhea. pdf \#zoom $=100>($ Accessed August 15, 2012) .

6. Small DM, Dowling RH, Redinger RN. The enterohepatic circulation of bile salts. Arch Intern Med 1972;130:552-73. 
7. Redinger RN. The role of the enterohepatic circulation of bile salts and nuclear hormone receptors in the regulation of cholesterol homeostasis: Bile salts as ligands for nuclear hormone receptors. Can J Gastroenterol 2003;17:265-71.

8. Fuchs M. Bile acid regulation of hepatic physiology: III. Regulation of bile acid synthesis: Past progress and future challenges. Am J Physiol Gastrointest Liver Physiol 2003;284:G551-7.

9. Swell L, Gustafsson J, Schwartz CC, Halloran LG, Danielsson H, Vlahcevic ZR. An in vivo evaluation of the quantitative significance of several potential pathways to cholic and chenodeoxycholic acids from cholesterol in man. J Lipid Res 1980;21:455-66.

10. Martínez-Augustin O, Sánchez de Medina F. Intestinal bile acid physiology and pathophysiology. World J Gastroenterol 2008;14:5630-40.

11. Lu TT, Makishima M, Repa JJ, et al. Molecular basis for feedback regulation of bile acid synthesis by nuclear receptors. Mol Cell 2000;6:507-15.

12. Kim I, Ahn SH, Inagaki T, et al. Differential regulation of bile acid homeostasis by the farnesoid $\mathrm{X}$ receptor in liver and intestine. J Lipid Res 2007;48:2664-72.

13. Craddock AL, Love MW, Daniel RW, et al. Expression and transport properties of the human ileal and renal sodium-dependent bile acid transporter. Am J Physiol 1998;274:G157-69.

14. Song KH, Li T, Owsley E, Strom S, Chiang JY. Bile acids activate fibroblast growth factor 19 signaling in human hepatocytes to inhibit cholesterol 7alpha-hydroxylase gene expression. Hepatology 2009;49:297-305.

15. Zweers SJ, Booij KA, Komuta M, et al. The human gallbladder secretes fibroblast growth factor 19 into bile: Towards defining the role of fibroblast growth factor 19 in the enterobiliary tract. Hepatology 2012;55:575-83.

16. Thomas LA, Veysey MJ, Bathgate T, et al. Mechanism for the transit-induced increase in colonic deoxycholic acid formation in cholesterol cholelithiasis. Gastroenterology 2000;119:806-15.

17. Stadler J, Stern HS, Yeung KS, et al. Effect of high fat consumption on cell proliferation activity of colorectal mucosa and on soluble faecal bile acids. Gut 1988;29:1326-31.

18. Hardison WG. Hepatic taurine concentration and dietary taurine as regulators of bile acid conjugation with taurine. Gastroenterology 1978;75:71-5.

19. Jung D, Fantin AC, Scheurer U, Fried M, Kullak-Ublick GA. Human ileal bile acid transporter gene ASBT (SLC10A2) is transactivated by the glucocorticoid receptor. Gut 2004;53:78-84.

20. Garbutt JT, Kenney TJ. Effect of cholestyramine on bile acid metabolism in normal man. J Clin Invest 1972;51:2781-9.

21. Chadwick VS, Gaginella TS, Carlson GL, Debongnie JC, Phillips SF, Hofmann AF. Effect of molecular structure on bile acid-induced alterations in absorptive function, permeability, and morphology in the perfused rabbit colon. J Lab Clin Med 1979;94:661-74.

22. Mekhjian HS, Phillips SF, Hofmann AF. Colonic secretion of water and electrolytes induced by bile acids: Perfusion studies in man. J Clin Invest 1971;50:1569-77.

23. Bajor A, Gillberg PG, Abrahamsson H. Bile acids: Short and long term effects in the intestine. Scand J Gastroenterol 2010;45:645-64.

24. Chiang JY. Bile acids: Regulation of synthesis. J Lipid Res 2009;50:1955-66.

25. Mekhjian HS, Phillips SF, Hofmann AF. Colonic absorption of unconjugated bile acids: Perfusion studies in man. Dig Dis Sci 1979;24:545-50.

26. McJunkin B, Fromm H, Sarva RP, Amin P: Factors in the mechanism of diarrhea in bile acid malabsorption: Fecal $\mathrm{pH}$ - a key determinant. Gastroenterology 1981;80:1454-1464.

27. Pattni S, Walters JRF. Recent advances in the understanding of bile acid malabsorption. Br Med Bull 2009;92:79-93.

28. Khalid U, Lalji A, Stafferton R, Andreyev J. Bile acid malabsoption: A forgotten diagnosis? Clin Med 2010;10:124-6.

29. Sadik R, Abrahamsson H, Ung KA, Stotzer PO. Accelerated regional bowel transit and overweight shown in idiopathic bile acid malabsorption. Am J Gastroenterol 2004;99:711-8.

30. van Tilburg AJ, de Rooij FW, van den Berg JW, van Blankenstein M. Primary bile acid malabsorption: A pathophysiologic and clinical entity? Scand J Gastroenterol (Suppl) 1992;194:66-70.

31. Törnblom H, Van Oudenhove L, Sadik R, Abrahamsson H, Tack J, Simrén M. Colonic transit time and IBS symptoms: What's the link? Am J Gastroenterol 2012;107:754-60.

32. Sciarretta G, Fagioli G, Furno A, et al. 75Se HCAT test in the detection of bile acid malabsorption in functional diarrhoea and its correlation with small bowel transit. Gut 1987;28:970-5.
33. Wong BS, Camilleri M, Carlson PJ, et al. A Klotho $\beta$ variant mediates protein stability and associates with colon transit in irritable bowel syndrome with diarrhea. Gastroenterology 2011;140:1934-42.

34. Wong BS, Camilleri M, Carlson P, et al. Increased bile acid biosynthesis is associated with irritable bowel syndrome with diarrhea. Clin Gastroenterol Hepatol 2012;10:1009-15.

35. Walters JR, Tasleem AM, Omer OS, Brydon WG, Dew T, le Roux CW. A new mechanism for bile acid diarrhea: Defective feedback inhibition of bile acid biosynthesis. Clin Gastroenterol Hepatol 2009;7:1189-94.

36. Grundy SM, Ahrens EH Jr, Miettinen TA. Quantitative isolation and gas-liquid chromatographic analysis of total fecal bile acids. J Lipid Res 1965;6:397-410.

37. Porter JL, Fordtran JS, Santa Ana CA, et al. A simple and accurate enzymatic method for measurement of total fecal bile acids in patients with severe fat malabsorption. J Lab Clin Med 2003;141:411-8.

38. Fromm H, Hofmann AF. Breath test for altered bile acid metabolism. Lancet 1971;ii:621-5.

39. Balzer K, Breuer N, Quebe-Fehling E. [Postprandial serum bile acid level and 75SeHCAT retention in diagnosis of bile acid malabsorption syndrome. A comparative study]. Med Klin (Munich) 1993;88(Suppl 1):23-8.

40. Sciarretta G, Vicini G, Fagioli G, Verri A, Ginevra A, Malaguti P. Use of 23-selena-25-homocholyltaurine to detect bile acid malabsorption in patients with illeal dysfunction or diarrhea. Gastroenterology 1986;91:1-9.

41. Boyd GS, Merrick MV, Monks R, et al. Se-75-labelled bile acid analogs, new radiopharmaceuticals for investigating the enterohepatic circulation. J Nuci Med 1981;22:720-5.

42. Nyhlin H, Merrick MV, Eastwood MA, Brydon WG. Evaluation of ileal function using 23-selena-25-homotaurocholate, a $\gamma$-labelled conjugated bile acid. Gastroenterology 1983; 84:63-8.

43. Bajor A, Kilander A, Sjövall H, Rudling M, Ung KA. The bile acid turnover rate assessed with the (75)SeHCAT test is stable in chronic diarrhoea but slightly decreased in healthy subjects after a long period of time. Dig Dis Sci 2008;53:2935-40.

44. Gälman C, Arvidsson T, Angelin B, Rudling M. Monitoring hepatic cholesterol 7 alpha-hydroxylase activity by assay of the stable bile acid intermediate 7 alpha-hydroxy-4-cholesten-3-one in peripheral blood. J Lipid Res 2003;44:859-66.

45. Eusufzai S, Axelson M, Angelin B, Einarsson K. Serum 7 alphahydroxy-4-cholesten-3-one concentrations in the evaluation of bile acid malabsorption in patients with diarrhoea: Correlation to SeHCAT test. Gut 1993;34:698-701.

46. Sauter GH, Munzing W, von Ritter C, Paumgartner G. Bile acid malabsorption a cause of chronic diarrhea: Diagnostic value of 7alpha-hydroxy-4-cholest-3-one in serum. Dig Dis Sci 1999;44:14-9.

47. Brydon WG, Culbert P, Kingstone K, et al. An evaluation of the use of serum 7-alpha-hydroxycholestenone as a diagnostic test of bile acid malabsorption causing watery diarrhea. Can J Gastroenterol 2011;25:319-23.

48. American Gastroenterological Association medical position statement: Guidelines for the evaluation and management of chronic diarrhea. Gastroenterology 1999;116:1461-3.

49. Borghede MK, Schlütter JM, Agnholt JS, Christensen LA, Gormsen LC, Dahlerup JF. Bile acid malabsorption investigated by selenium-75-homocholic acid taurine ((75)SeHCAT) scans: Causes and treatment responses to cholestyramine in 298 patients with chronic watery diarrhoea. Eur J Intern Med 2011;22:e137-40.

50. Lenicek M, Duricova D, Komarek V, et al. Bile acid malabsorption in inflammatory bowel disease: Assessment by serum markers. Inflamm Bowel Dis 2011;17:1322-7.

51. Kunstár E, Hegyi P, Rakonczay Jr Z, et al. Is bile acid malabsorption really a common feature of Crohn's disease or is it simply a consequence of ileal resection? Front Physiol 2011;2:28.

52. Nyhlin H, Merrick MV, Eastwood MA. Bile acid malabsorption in Crohn's disease and indications for its assessment using SeHCAT. Gut 1994;35:90-3.

53. Ford GA, Preece JD, Davies IH, Wilkinson SP. Use of the SeHCAT test in the investigation of diarrhea. Postgrad Med J 1992;68:272-6.

54. Sinha L, Liston R, Testa HJ, Moriarty KJ. Idiopathic bile acid malabsorption: Qualitative and quantitative clinical features and response to cholestyramine. Aliment Pharmacol Ther 1998;12:839-44. 
55. Sciarretta G, Bonazzi L, Monti M, et al. Bile acid malabsorption in AIDS-associated chronic diarrhea: A prospective 1-year study. Am J Gastroenterol 1994;89:379-81.

56. Cramp ME, Hing MC, Marriott DJ, Freund J, Cooper DA. Bile acid malabsorption in HIV infected patients with chronic diarrhoea. Aust N Z J Med 1996;26:368-71.

57. Ung KA, Kilander AF, Lindgren A, Abrahamsson H. Impact of bile acid malabsorption on steatorrhoea and symptoms in patients with chronic diarrhoea. Eur J Gastroenterol Hepatol 2000;12:541-7.

58. Smith MJ, Cherian P, Raju GS, Dawson BF, Mahon S, Bardhan KD. Bile acid malabsorption in persistent diarrhoea. J R Coll Physicians Lond 2000;34:448-51.

59. Wildt S, Nørby Rasmussen S, Lysgård Madsen J, Rumessen JJ. Bile acid malabsorption in patients with chronic diarrhoea: Clinical value of SeHCAT test. Scand J Gastroenterol 2003;38:826-30.

60. Müller M, Willén R, Stotzer PO. Colonoscopy and SeHCAT for investigation of chronic diarrhea. Digestion 2004;69:211-8.

61. Fernández-Bañares F, Esteve M, Salas A, et al. Systematic evaluation of the causes of chronic watery diarrhea with functional characteristics. Am J Gastroenterol 2007;102:2520-8.

62. Wedlake L, A'Hern R, Russell D, Thomas K, Walters JR, Andreyev HJ. Systematic review: The prevalence of idiopathic bile acid malabsorption as diagnosed by SeHCAT scanning in patients with diarrhoea-predominant irritable bowel syndrome. Aliment Pharmacol Ther 2009;30:707-17.

63. Kurien M, Evans KE, Leeds JS, Hopper AD, Harris A, Sanders DS. Bile acid malabsorption: An under-investigated differential diagnosis in patients presenting with diarrhea predominant irritable bowel syndrome type symptoms. Scand J Gastroenterol 2011;46:818-22.

64. Gracie DJ, Kane JS, Mumtaz S, Scarsbrook AF, Chowdhury FU, Ford AC. Prevalence of, and predictors of, bile acid malabsorption in outpatients with chronic diarrhea. Neurogastroenterol Motil 2012;24:983-e538.

65. Niaz SK, Sandrasegaran K, Renny FH, Jones BJ. Postinfective diarrhoea and bile acid malabsorption. J R Coll Physicians Lond 1997;31:53-6.

66. Menon S, Jones BJ. Postinfective bile acid malabsorption: Is this a long-term condition? Eur J Gastroenterol Hepatol 2011;23:308-10.

67. Nakamura T, Kikuchi H, Takebe K, et al. Correlation between bile acid malabsorption and pancreatic exocrine dysfunction in patients with chronic pancreatitis. Pancreas 1994;9:580-4.
68. Lanzini A, Lanzarotto F. Review article: The 'mechanical pumps' and the enterohepatic circulation of bile acids - defects in coeliac disease. Aliment Pharmacol Ther 2000;14(Suppl 2):58-61.

69. Sciarretta G, Furno A, Mazzoni M, Malaguti P. Postcholecystectomy diarrhea: Evidence of bile acid malabsorption assessed by SeHCAT test. Am J Gastroenterol 1992;87:1852-4.

70. Sauter GH, Moussavian AC, Meyer G, Steitz HO, Parhofer KG, Jüngst $\mathrm{D}$. Bowel habits and bile acid malabsorption in the months after cholecystectomy. Am J Gastroenterol 2002;97:1732-5.

71. Stein TA, Nilsson LO, Burns GP, Mandell C, Wise L. Changes in bile salt composition after cholecystectomy and ileal resection. Am J Surg 1985;150:361-4.

72. al-Hadrani A, Lavelle-Jones M, Kennedy N, Neill G, Sutton D, Cuschieri A. Bile acid malabsorption in patients with postvagotomy diarrhoea. Ann Chir Gynaecol 1992;81:351-3.

73. Canadian Digestive Health Foundation. Irritable bowel syndrome. <www.cdhf.ca/digestive-disorders/ibs.shtml> (Accessed September 10, 2012).

74. Luman W, Williams AJ, Merrick MV, Eastwood MA. Idiopathic bile acid malabsorption: Long-term outcome. Eur J Gastroenterol Hepatol 1995;7:641-5.

75. Olestyr (cholestyramine) Product Monograph. Pendopharm, Division of Pharmascience Inc, February 20, 2012.

76. Colestid (colestipol) Product Monograph. Pfizer Canada Inc., November 6, 2012.

77. Lodalis (colesevelam) Product Monograph. Valeant Canada LP, December 22, 2011.

78. Odunsi-Shiyanbade ST, Camilleri M, McKinzie S, et al. Effects of chenodeoxycholate and a bile acid sequestrant, colesevelam, on intestinal transit and bowel function. Clin Gastroenterol Hepatol 2010;8:159-65.

79. Wedlake L, Thomas K, Lalji A, Anagnostopoulos C, Andreyev HJ. Effectiveness and tolerability of colesevelam hydrochloride for bileacid malabsorption in patients with cancer: $\mathrm{A}$ retrospective chart review and patient questionnaire. Clin Ther 2009;31:2549-58.

80. Walters JRF, Pattni SS. Managing bile acid diarrhea. Ther Adv Gastroenterol 2010;3:349-57.

81. West RJ, Lloyd JK. The effect of cholestyramine on intestinal absorption. Gut 1975;16:93-8.

82. Jacobson TA, Armani A, McKenney JM, Guyton JR. Safety considerations with gastrointestinally active lipid-lowering drugs. Am J Cardiol 2007;99:47C-55C. 


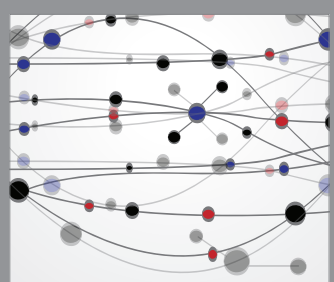

The Scientific World Journal
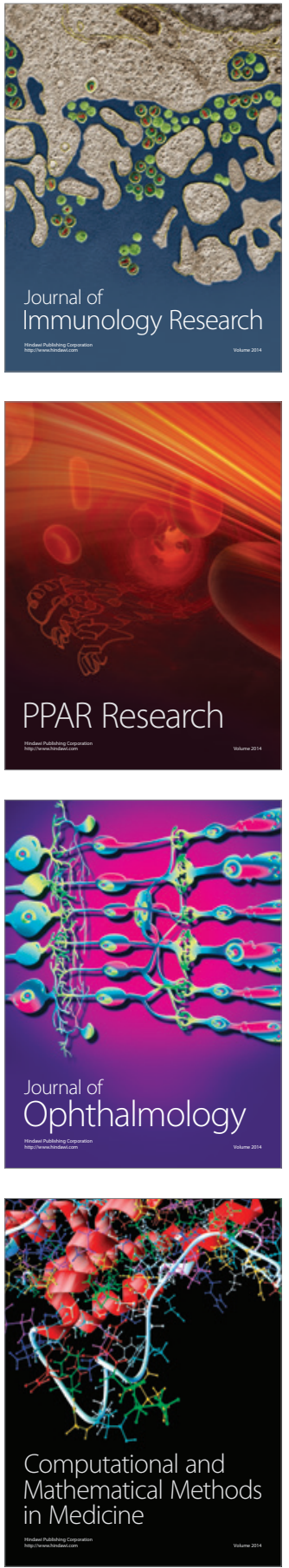

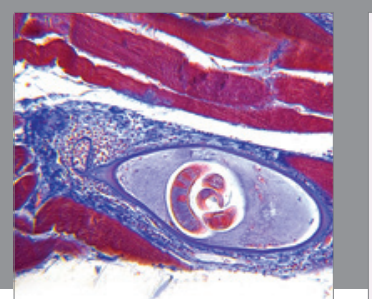

Gastroenterology Research and Practice

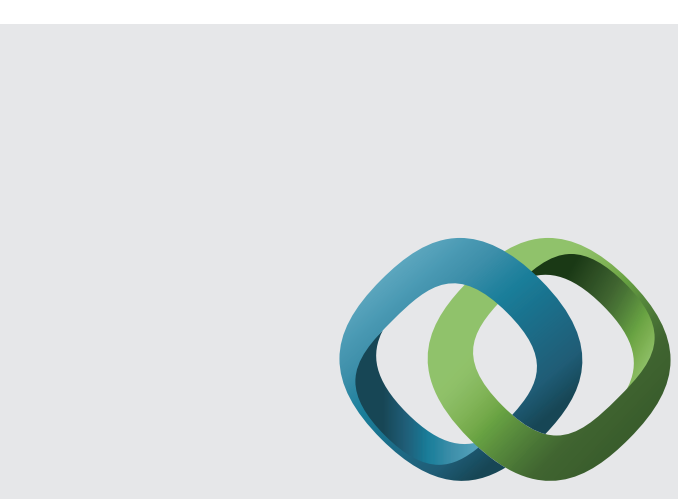

\section{Hindawi}

Submit your manuscripts at

http://www.hindawi.com
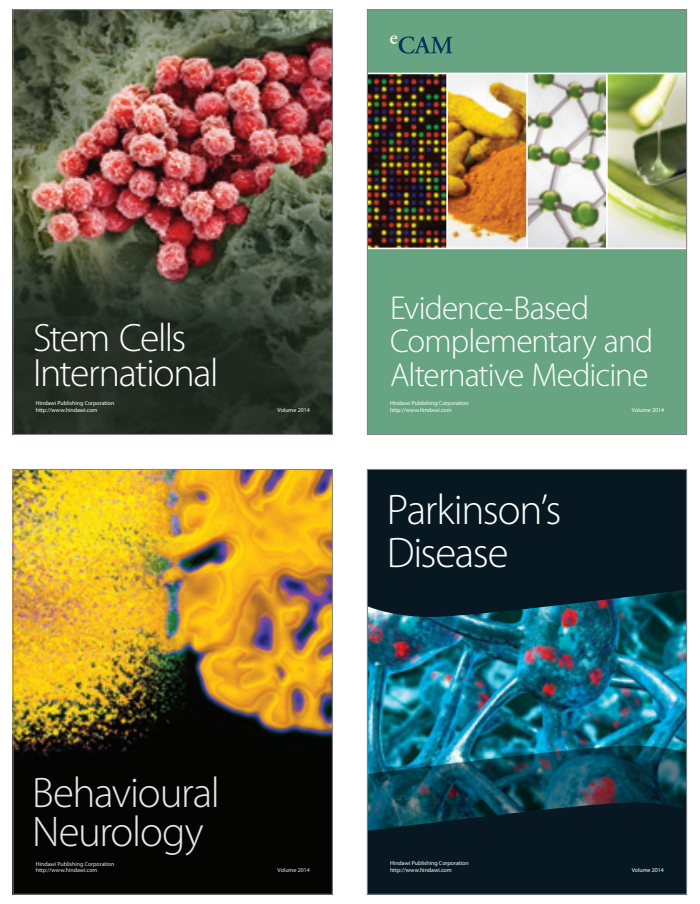
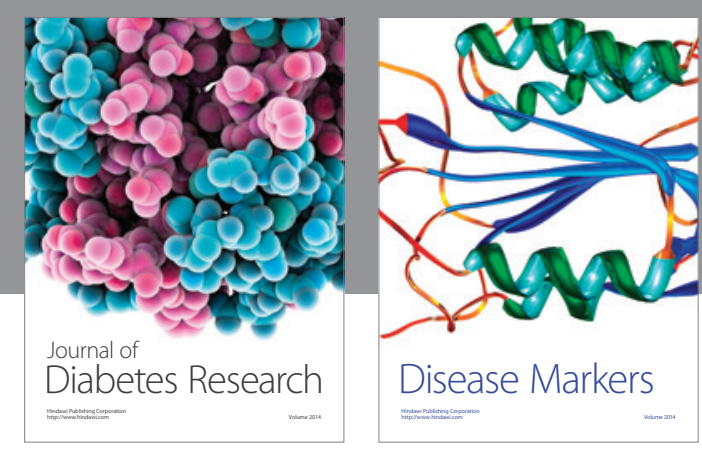

Disease Markers
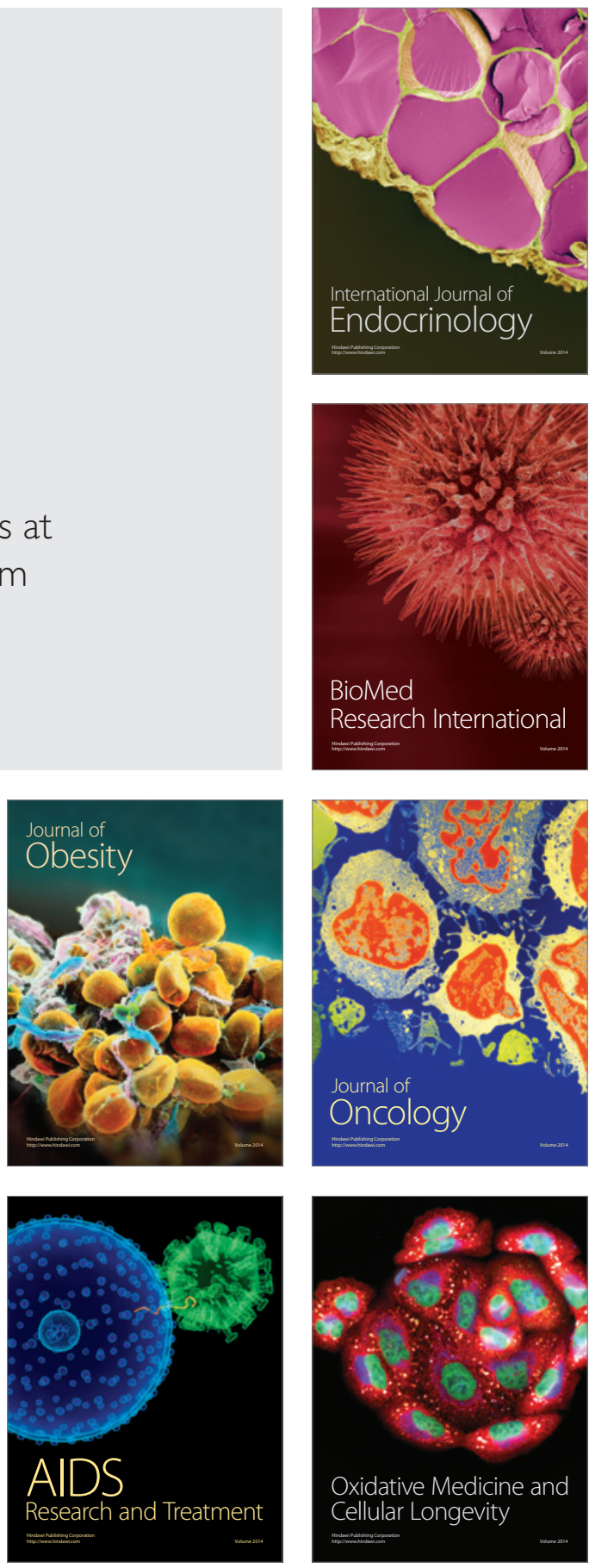